\title{
PENGARUH INTENSITAS KEBISINGAN TERHADAP FREKUENSI DENYUT NADI PADA PEKERJA PENGGILINGAN GABAH DI DESA SANGLEPONGAN KECAMATAN CURIO KABUPATEN ENREKANG
}

\author{
The Effect of Noise Intensity on the Pulse Rate Frequency On Grain Milling Workers in \\ Sanglepongan Village, Curio District Enrekang \\ Masdi, Rahmi Amir, Amir Patintingan \\ Program Studi Kesehatan Masyarakat Fakultas Ilmu Kesehatan Universitas Muhammadiyah \\ Parepare \\ (masdi3998@gmail.com)
}

\begin{abstract}
ABSTRAK
Kebisingan merupakan salah satu masalah kesehatan lingkungan dan kesehatan kerja.Bising adalah suara yang tidak dikehendaki yang dapat menganggu dan atau dapat membahayakan kesehatan. Berdasarkan kepmenaker,kebisingan adalah suara yang tidak dikehendaki yang bersumber dari alatalat, proses produksi yang pada tingkat tertentu dapat menimbulkan gangguan kesehatan dan pendengaran Tujuan dari penelitian ini adalah untuk mengetahui pengaruh intensitas kebisingan dengan frekuensiDenyut Nadi pada Pekerja penggilingan Gabah Di Desa Sanglepongan Kecamatan Curio Kabupaten Enrekang, dan Untuk mengetahui dampak kesehatan bagi pekerja penggilingan gabah di Desa Sanglepongan Kecamatan Curio Kabupaten Enrekang. Metode dalam penelitian ini adalah survei analitik dengan pendekatan cross sectional. Berdasarkan hasil penelitian dan uji statistic yang telah dilakukan dihasilkan $t$ hitung yakni 6,000 dengan tingkat signifikansi yakni 0,000 yang artinya ada perbedaan antara frekuensi denyut nadi sebelum dan setelah terpapar kebisingan.
\end{abstract}

Kata kunci : Penggiling gabah, kebisingan, frekuensi denyut nadi

\begin{abstract}
Noise is one of the problems of environmental health and occupational health. Bising is an unwanted sound that can disturb and or can endanger health. Based on the ministerial decree, noise is an undesirable sound originating from tools, a production process that at a certain level can cause health and hearing impairments The purpose of this study is to determine the effect of noise intensity with the pulse rate on Grain Grain Workers in Sanglepongan Village, Curio District, Enrekang Regency, and To find out the health effects of grain grinding workers in Sanglepongan Village, Curio District, Enrekang Regency. The method in this study is an analytical survey with a cross sectional approach. Based on the results of the research and statistical tests that have been carried out, $t$ count is 6,000 with a significance level of 0,000 which means there is a difference between the pulse frequency before and after exposure to noise.
\end{abstract}

Keywords: Grain grinder, noise, pulse frequency 


\section{PENDAHULUAN}

Setiap tenaga kerja memiliki kepekaan sendiri-sendiri terhadap kebisingan,terutama nada yang tinggi, karena adanya reaksi pisikologi seperti stres, kelelahandan hilang efisiensi.Kebisingan merupakan salah satu faktor bahaya fisik yang sering di jumpai di lingkungan kerja. Di lingkungan kerja, kebisingan merupakanmasalah kesehatan kerja yang selalu timbul pada industri, seperti pabrik semen, pabrik pemecah batu dan pabrik penggilingan gabah.

Hubungan antara kebisingan dengan kemungkinan timbulnya gangguan terhadap kesehatan sangat dipengaruhi oleh beberapa faktor yaitu intensitas kebisingan, frekuensi kebisingan, dan lamanya seseorang berada di tempat atau didekat bunyi tersebut, baik dari hari ke hari ataupun seumur hidupnya.Dari segi kesehatan, tingkat kebisingan yang dapat diterima tergantung pada bebarapa lama kebisngan tersebut diterima.Berbagai penelitian di beberapa negara mendapatkan tingkat kebisingan yang dapat diterima dipemukiman. Tingkat kebisngan yang dapat ditolerir oleh seseorang tergantung pada kegiatan apa yang sedang dilakukan oleh orang tersebut. Seseorang yang sedang sakit atau beribadah akan terganggu oleh kebisingan yang rendah sekalipun. ${ }^{1}$

Aktivitas produksi pada usaha pabrik penggilingan gabah dilakukan setiap hari, dalam hal ini setiap pagi dan sore.Dalam jangka waktu tersebut, usaha ini dapat melayani beberapa pelanggandengan jumlah produksi yang lumayan banyak, tergantung dari banyaknya pengunjung yang datang per harinya.Kapasitas 2 produksi mesin penggilingan gabah yang digunakan biasanya mencapai 15 karung/225kg per hari, dalam satu karung rata-rata berisikan $15 \mathrm{~kg}$ beras dengan jangka waktu yang di butuhkan untuk melakukan penggilingan tersebut yaitu biasanya 4-5 jam. Selain itu, pelanggan atau pengunjung yang menggunakan industri tersebut adalah skala rumah tangga sehingga jumlah gabah yang akan digiling tidak terlalu banyak di banding dengan industri skala besar yang ada beberapa wilayah.

Aktivitas utama dari usaha penggilingan gabah itu adalah melakukan pengolahan gabah menjadi beras, Dimana mesin dari penggilingan tersebut tediri dari 2 bagian yaitu mesin perontok dan mesin pengupas.Usaha ini memiliki aktivitas pengolahan gabah dan penjualan beras. Aktivitas atau usaha penjualan beras dilakukan dua hari dalam seminggu yaitu hari selasa dan jumat(pasar Sudu). Namun jam kerja dari usaha ini lebih sedikit dibandingkan dengan usaha industri skala besar, yaitu kurang lebih 4 jam per hari, tergantung dari banyaknya pengunjung atau pelanggan yang datang. Aktivitas yang dilakukan oleh usaha penggilingan gabah dalam tiaptahapannya memiliki biaya yang harus ditanggung oleh pemilik usaha penggilingan itu.Biaya tetap dikeluarkan oleh penggilingan meliputi biaya 
penyusutan mesin dan peralatan. Teknologi modern memberikan hasil yang positif dan juga memberikan efek yang negatif pula yaitu berupa gangguan kesehatan dan keselamatan bagi tenaga kerja maupun masyarakat sekitarnya.Efek negative tersebut bisa timbul dari penyakit akibat kerja yang ada dalam ruang/tempat kerja yang dibagi dalam 53 golongan yaitu golongan fisik, kimia, biologi, fisiologi dan mental psikologi ${ }^{2}$.

Produktivitas tenaga kerja menurun dikarenakan beberapa faktor antara lain: meja atau yang kursi tidak ergonomis, kebosanan dalam bekerja dan kelelahan dalam melakukan aktivitas pekerjaannya. Kebisingan merupakan salah satu faktor fisik lingkungan kerja yang dapat menimbulkan dampak pada gangguan pendengaran (audiotory) dan extra audiotory seperti stress kerja/psikologik, hipertensi, kelelahan kerja dan perasaan tidak senang.Kebisingan didefinisikan sebagai segenap bunyi yang tidak dikehendaki.Bising adalah bunyi yang tidak dikehendaki yang merupakan aktivitas alam maupun buatan manusia (bunyi mesin).Secara umum bising adalah bunyi yang tidak diinginkan. Pada berbagai penyelidikan ditemukan bahwa pemaparan bunyi terutama yang mendadakmenimbulkan reaksi fisiologis seperti: denyut nadi, tekanan darah, metabolisme, gangguan tidur dan penyempitan pembuluh darah. Reaksi ini terutama terjadi pada permulaan pemaparan terhadap bunyi kemudian akankembali pada keadaan semula.
Bila terus menerus terpapar maka akan terjadi adaptasi sehingga perubahan itu tidak tampak lagi. Kebisingan dapat menimbulkan gangguan fisiologis melalui sistem internal tubuh, Dimana sistem internal tubuh adalah sistem fisiologis yang penting untuk kehidupan seperti: Kardiovaskuler (jantung, paru-paru, pembuluh), Gastrointestinal (perut,usus), Syaraf (urat syaraf), Musculoskeletal (otot, tulang) dan Endocrine (kelenjar) . ${ }^{3}$

Berdasarkan latar belakang di atas maka penulis tertarik untuk meneliti pengaruh intensitas kebisingan terhadap kenaikan denyut nadi pada pekerja penggilingan gabah Di Desa Sanglepongan Kecamatan Curio Kabupaten Enrekang.

\section{BAHAN DAN METODE}

Jenis penelitian yang digunakan pada penelitian ini adalah survei analitikdengan pendekatan cross sectional. Penelitian cross sectional ini merupakan suatu penelitian (survei) analitik yang menyangkut bagaiman pengaruh intensitas kebisingan dengan frekuensi denyut nadi pada pekerja penggilingan gabah. Desain penelitian yang di gunakan dalam penelitian ini adalah Observasi.

Populasi dan sampel dalam penelitian ini adalah semua pekerja penggilingan gabah di Desa Sanglepongan yang berjumlah 10 orang yang di ambil dari 5 pabrik gabah yang ada di Desa 
Sanglepongan. Dalam mengumpulkan data yang dibutuhkan untuk menyusun penelitian ini, penulis menggunakan beberapa metode, alat dan yang digunakan, yaitu Sound level meter, Stetoskop, Alat tulis menulis. Data Primer yang di peroleh langsung dengan pengamatan,dan rata rata jumlah nilai responden.Sedangkan data skunder data yang diperoleh dari hasil penelitian dikelompokkan agar memudahlan dalam analisis, selanjutnya data di sajikan dalam bentuk tabel on grafik.

\section{HASIL}

Distribusi frekuensi responden berdasarkan umur di pabrik penggilingan gabah Desa Sanglepongan Kecamatan Curio Kabupaten Enrekang kebanyakan adalah lakilaki dengan umur antara 30-39 sebanyak 4 orang $(36,4 \%)$ dan $40-49$ sebanyak 4 orang $(36,4 \%)$ dan terendah dengan umur antara 5059 sebanyak 1 orang $(9,1 \%)$ dan 60-69 sebanyak 1 orang $(9,1 \%)$. Distribusi frekuensi responden berdasarkan berat badan pada penelitian ini dimana berat badan lebih banyak terdapat pada berat badan rentang antara 60-69 sebanyak 6 orang $(54,5 \%), 70-79$ sebanyak 2 orang $(18,2 \%)$ dan paling rendah adalah $40-$ 49 sebanyak 1 oramng $(9,1 \%)$ dan 50-59 sebanyak 1 oramng $(9,1 \%)$. Distribusi Frekuensi Responden berdasarkan Tingkat Pendidikan dimana jenjang pendidikan tertinggi pada SMP sebanyak 5 orang $(45,5 \%)$ dan terendah di tingkat SMA sebanyak 2 orang (18,2\%). Distribusi responden berdasarkan lamanya responden telah bekerja di pabrik penggilingan gabah tersebut diman kebanayakan responden telah bekerja di pabrik tersebut terdapat pada kisaran 6-10 tahun sebnayak 7 orang $(63,6 \%)$ dan terendah kisaran umur 21-25 sebanyak 1 orang (9,1\%).

Berdasarkan penelitian yang dilakukan terhadap 10 responden hasil pengukuran kenaikan denyut nadi. Distribusi Frekuensi Responden berdasarkan Denyut Nadi Responden didapatkan yang paling tertinggi yaitu dengan denyut nadi 95 sebnayak 1 orang dan denyut nadi tererndah 60 sebanyak 2 orang. Distribusi Frekuensi Responden berdasarkan Denyut Nadi Responden Setelah Terpapar Kebisingan Sebelum Terpapar Kebisingan didapatkan yang paling tertinggi yaitu dengan denyut nadi 96 sebanyak 2 orang dan terendah 60 sebayank 1 orang. Kenaikan Denyut Nadi Responden Sebelum Dan Setelah Terpapar Kebisingan pada Penggilingan Padi Desa Sanglepongan Kec.Curio didapatkan kenaikan denyut nadi setelah terpapar kebisingan atau setelah mesin beroperasi yakni 8 responden (80\%) dan 2 responden (20.0\%) dengan denyut nadi tetap atau tidak mengalami kenaikan denyut nadi.

Berdassarkan penelitian yang telah dilakukan diperoleh hasil pengukuran intensitas kebisingan di bagian luar dan dalam area penggilingan, Hasil Pengukuran Intensitas Kebisingan di Luar Area 
Penggilingan Gabah Desa Sanglepongan Kecamatan Curio Kabupaten Enrekang diketahui bahwa rata-rata intensitas kebisingan di arealuar penggilingan dari ke lima penggilingan yang ada yaitu 81,02 dB. Dan dari hasil pengukuran tersebut dapat dilihat bahwa untuk area luar penggilingan rata-rata intensitas kebisingan penggilingan yang area luarnya melebihi NAB yaitu area luar penggilingan 4 yakni $91,7 \mathrm{~dB}$. Hasil Pengukuran Intensitas Kebisingan di Area Penggilingan Gabah Desa Sanglepongan Kecamatan Curio Kabupaten Enrekang didapatkan hasil rata-rata intensitas kebisingan area yang tidak melebihi NAB yaitu 89.814. Pengaruh Intensitas Kebisingan di Area Penggilingan dengan Kenaikan Denyut Nadi di Penggilingan Gabah di Desa Sanglepongan Kecamatan CurioKabupaten Enrekang, Berdasarkan hasil penelitian dan uji statistic yang telah dilakukan dihasilkan $\mathrm{t}$ hitung yakni 6,000 dengan tingkat signifikansi yakni 0,000 yang artinya ada perbedaan antara frekuensi denyut nadi sebelum dan setelah terpapar kebisingan. Hal ini dikarenakan kondisi bising dapat menyebabkan pekerja mengalami kelelahan dimana jika terjadi kelelahan maka akan menyebabkan jantung akan bekerja keras untuk memompa darah sehingga denyut nadi juga akan meningkat .kenaikan denyut nadi juga disebabkan karena para pekerja melakukan suatu pekerjaan dalam keadaan berdiri. Yang mana diketahui bahwa denyut nadi dalam keadaan berdiri berbeda dengan pada saat duduk, begitupun dengan dalam keadaan bekerja.Selain kebisingan, hal ini merupakan salah satu yang dapat menyebabkan seorang mengalami peningkatan denyut nadi setelah bekerja.

\section{PEMBAHASAN}

Intensitas di lingkungan penggilingan gabah yang ada di Desa Sanglepongan ada 3 yang tidak memenuhi syarat( berisiko), terdapat pada lingkungan kerja area penggilingan 1,3dan 5 . ada perbedaan antara intensitas kebisingan di setiap tempat penggilingan yang lain. Hal ini disebabkan karena setiap penggilingan letak geografisnya berbeda, adanya mesin-mesin yang sudah cukup lama atau boleh dikatakan sudah tua , dan ruangan tidak memiliki kedap.

Sementara hasil pengukuran kebisingan yang sudah dilakukan di penggilingan gabah yang ada di desa Sanglepongan yang diambil di 5 titik luar dan dalam masing-masing penggilingan menggunakan alat sound level meter didapatkan nilai kebisingan tertinggi yakni 92,61 dBA.sedangkan tingkat kebisingan terendah untuk area dalam penggilingan yaitu 82,87 . Hal ini menunjukkan bahwa nilai rataratakebisingan di bagian dalam area penggilingan gabah melebihi NAB (Nilai Ambang Batas) yang ditetapkan bagi pekerja selama 2 jam sehari. Sedangkan di area luar penggilingan sebagi pembanding dari hasil pengukuran kebisingan yang diambil dari 5 
titik dengan tingkat kebisingan tertinggi 91,7 dBA dan tingakt kebisingan terendah yakni 62,92 dBA untuk rata- rata kebisingan 81.02 dBA. Hal ini juga sebenarnya bisa dikatakan cukup tinggi namun untuk pekerja yang hanya bekerja dibawah 8 jam perhari masih dalam batas normal. Dengan kebisingan dibawah nilai ambang batas yang telah ditentukan di area luar masing-masing penggilingan masih cukup aman bagi pekerja.Hanya ada satu penggilingan yang area luarnya melebih nilai ambang batas. Hal ini dekarenakan terlalu kecilnya ruang penggilingan sehingga suara yang dikeluarkan oleh mesin tersebar keluar dan menyebabkan kebisingan di laur area penggilingan yang akan memberikan dampak bagi masyarkat yang ada di sekitar penggilingan karena penggilingan gabah yang ada di desa Sanglepongan dekat dari pemukiman masyarakat. Dari hasil pengukuran denyut nadi pekerja yang telah dilakukan sebagian diperoleh rata-rata frekuensi denyut nadi pekerja sebelum bekerja adalah 65,3 denyut per menit, sedangkan ratarata denyut nadi setelah kerja atau setalah mesin beroperasi adalah 86,9 denyut per menit. Dengan demikian terjadi kenaikan frekuensi denyut nadi pekerja yang bekerja di penggilingan gabah desaSanglepongan ini.

Berdasarkan hasil uji statistic yang dilakukan dengan menggunakan uji paired ttest menunjukkan bahwa hasil yang didaptkan t hitung 6,000 dengan tingkat signifikansi (p) 0,000 karena tingkat signifikansi kurang dari
0,05 atau $\mathrm{p} \leq 0,05$, maka $\mathrm{H} 0$ ditolak . nilai tersebut menunjukkan bahwa ada perbedaan signifikan antara denyut nadi sebelum bekerja dan setelah bekerja, sehingga ada pengaruh kebisingan terhadap kenaikan denyut nadi pada pekerja di penggilingan gabah desa Sanglepongan kecamatan Curio Kabupaten Enrekang. Kebisingan yang terjadi di penggilingan gabah desa Sanglepongan ini akan berdampak negative bagi kesehatan masyarakat utamanya bagi pekerja juga bagi masyarakat yang ada di sekitar pabrik penggilingan gabah ini. Hal ini karena para pekerja tidak ada yang menggunakan alat pelindung diri yang dapat melindungi dirinya dari efek kebisingan ini, apalagi para pekerja sudah bekerja begitu lam di pabrik ini. Bunyi mesin yang ada secara mendadak dan terus menerus selama 2 jam dan secara cepat akan diikuti oleh reflek otot di telinga yang akan membatasi jumlah suara yang dihantarkan ke telinga dalam. Hal ini jika terus menerus seperti ini dalam waktu yang cukup lama akan merusak organ korti pekerja juga masyarakat dan dapat pula mengakibatkan ketulian permanen pada pekerja.

\section{KESIMPULAN DAN SARAN}

Berdasarkan hasil penelitian yang telah dilakukan di Desa Sanglepongan Keacamatan Curio Kabupaten Enrekang selama bulan Mei sampai September 2018 maka dapat ditarik kesimpulan sebagai berikut: Ada pengaruh intensitas kebisingan 
terhadap freskuensi denyut nadi pada pekerja penggilingan gabah di Desa Sanglepongan Keacamatan Curio Kabupaten Enrekang dengan nilai t hitung yakni 6,000 dengan $\mathrm{p}=$ 0,000 atau p\&lt: 0,005. Sebaiknya dapat dilakukan pengendalian kebisingan, dengan

\section{DAFTAR PUSTAKA}

1. Daniel Haris Sukmono. Pengaruh Kebisingan Terhadap Tingkat Kelelahan Kerja Di Penggilingan Padi Desa Griyan Kelurahan Baturan Kecamatan Colomadu Kabupaten Karanganyar; 2010.

2. Jennie Babba. Hubungan Antara Intensitas Kebisingan Di Lingkungan Kerja Dengan Peningkatan Tekanan Darah. Jember; 2007.

3. Nenga Sandi. Pengaruh Latihan Fisik Terhadap Frekuensi Denyut Nadi Kabupaten Karanganyar; 2016.

4. Tri Budiyanto. Hubungan Kebisingan Pada Masa Kerja Terhadap Terjadinya Sters Kerja Pada Pekerja Di Bagian Tenun "Agung Saputra Tex" Piyungan Bantul Yogyakarta. Yogyakarta; . 2010.

5. Susanti Djalante. Analisis Tingkat Kebisingan Di Jalan Raya Yang melakukan perawatan mesin secara berkala agar meminimalisir tingkat kebisingan dan diharapkan kepada pekerja untuk lebih meningkatkan kesadaran dalam penggunaan alat pelindung diri (APD) khususnya alat pelindung telinga.

Menggunakan Alat Pemberi Isyarat Lalu Lintas (APIL); 2010.

6. Tri Budiyanto. Hubungan Kebisingan Dan Massa Kerja Terhadap Terjadinya Stres Kerja Pada Pekerja Di Bagian Tenun “Agung Saputra Tex" Piyungan Bantul Yograkarta; 2010.

7. Tajuddin Bantacut. Teknologi Pengolahan Padi Terintegrasi Berwawasan Lingkungan; 2006.

8. Prawida Gali Saputro. Pengaruh Kebisingan Terhadap Kelelahan Umum Pada Tenaga Kerja Penggilingan Padi di Desa Kakogan Sukohargo; 2011.

9. Ikron, dkk. Pengaruh Kebisingan Lalu Lintas Jalan Terhadap Gangguan Kesehatan Psikologis Anak SDN Cipinang Muara Kecamatan Jatinegara. Kota Jakarta Timur: Propinsi DKI Jakarta: 2005. 


\section{LAMPIRAN}

Tabel 1. Distribusi Frekuensi Responden berdasarkan Umur

\begin{tabular}{ccc}
\hline Umur (Tahun) & Frekuensi & Persentase \\
\hline $30-39$ & 4 & 36.4 \\
$40-49$ & 4 & 36.4 \\
$50-59$ & 1 & 9.1 \\
$60-69$ & 1 & 9.1 \\
& & \\
\hline Total & 10 & 100.0
\end{tabular}

Sumber : Data Primer (2018)

Tabel 2. Distribusi Frekuensi Responden Berdasarkan Berat Badan

\begin{tabular}{cccc}
\hline Berat Badan $(\mathrm{kg})$ & Frekuensi & Persentase \\
\hline $40-49$ & 1 & 9.1 \\
\hline $50-59$ & 1 & 9.1 \\
\hline $60-69$ & 6 & 54.5 \\
\hline $70-79$ & 2 & 18.2 \\
Total & 10 & 100.0 \\
\hline
\end{tabular}

Sumber : Data Primer (2018)

Tabel 3. Distribusi Frekuensi Responden berdasarkan Tingkat Pendidikan

\begin{tabular}{cc|cc}
\hline Tingkat Pendidikan & Frekuensi & Persentase \\
\hline Sekolah Dasar & 3 & 27.3 & 45.5 \\
SMP & 5 & & 18.2 \\
SMA & 2 & 100.0 & \\
\hline Total & 11 & & \\
\hline
\end{tabular}

Sumber : Data Primer (2018)

Tabel 4. Distribusi Frekuensi berdasarkan Lama Bekerja Respondnen di Pabrik Penggilingan Gabah Desa Sanglepongan Kecamatan Curio

\begin{tabular}{ccc}
\hline Lama Bekerja & Frekuensi & Persentase \\
\hline $1-5$ & 2 & 18.2 \\
$6-10$ & 7 & 63.6 \\
$21-25$ & 1 & 9.1 \\
\hline Total & 10 & 100.0 \\
\hline
\end{tabular}

Sumber : Data Primer (2018) 
Tabel 5. Distribusi Frekuensi Responden berdasarkan Denyut Nadi Responden Sebelum Terpapar Kebisingan

\begin{tabular}{cc}
\hline Responden & Denyut Nadi \\
\hline 2 & 60 \\
1 & 62 \\
3 & 63 \\
1 & 65 \\
1 & 67 \\
1 & 70 \\
1 & 95 \\
\hline
\end{tabular}

Sumber : Data Primer (2018)

Tabel 6. Distribusi Frekuensi Responden berdasarkan Denyut Nadi Responden Setelah Terpapar Kebisingan

\begin{tabular}{cc}
\hline Responden & Denyut Nadi \\
\hline 1 & 60 \\
1 & 65 \\
1 & 80 \\
2 & 85 \\
2 & 90 \\
1 & 95 \\
2 & 96 \\
\hline
\end{tabular}

Sumber : Data Primer (2018)

Tabel 7. Kenaikan Denyut Nadi Responden Sebelum Dan Setelah Terpapar Kebisingan pada Penggilingan Padi Desa Sanglepongan Kec.Curio Kabupaten Enrekang

\begin{tabular}{ccc}
\hline Kenaikan Denyut Nadi & Frekuensi & Persentase \\
\hline Ya & 8 & 80.0 \\
Tidak & 2 & 20.0 \\
Total & 10 & 100.0
\end{tabular}

Sumber : Data primer (2018)

Tabel 8. Hasil Pengukuran Intensitas Kebisingan di Luar Area Penggilingan Gabah Desa Sanglepongan Kecamatan Curio Kabupaten Enrekang.

\begin{tabular}{cc|}
\hline Pengukuran Area Luar Penggilingan & Intensitas Kebisingan dB(A) \\
\hline Penggilingan 1 & 70.18 \\
Penggilingan 2 & 90.5 \\
Penggilingan 3 & 89.8 \\
Penggilingan 4 & 91.7 \\
Penggilingan 5 & 62.92 \\
\hline Rata-rata & 81.02 \\
\hline
\end{tabular}

Sumber: Data Primer (2018) 
Tabel 9. Hasil Pengukuran Intensitas Kebisingan di Area Penggilingan Gabah Desa Sanglepongan Kecamatan Curio Kabupaten Enrekang.

\begin{tabular}{cc|}
\hline Pengukuran Area Penggilingan & Intensitas Kebisingan $\mathrm{dB}(\mathrm{A})$ \\
\hline Penggilingan 1 & 92.29 \\
Penggilingan 2 & 89.7 \\
Penggilingan 3 & 91.6 \\
Penggilingan 4 & 82.87 \\
Penggilingan 5 & 92.61 \\
\hline Rata-rata & 89.814 \\
\hline
\end{tabular}

Sumber: Data Primer (2018)

Tabel 10. Pengaruh Intensitas Kebisingan di Area Penggilingan dengan Kenaikan Denyut Nadi di Penggilingan Gabah di Desa Sanglepongan Kecamatan Curio Kabupaten Enrekang.

\begin{tabular}{|c|c|c|c|c|c|c|c|c|c|}
\hline \multicolumn{10}{|c|}{ Paired Samples Test } \\
\hline & & \multicolumn{5}{|c|}{ Paired Differences } & \multirow[t]{3}{*}{$\mathrm{t}$} & \multirow[t]{3}{*}{ Df } & \multirow{3}{*}{$\begin{array}{l}\text { Sig. } \\
(2-\text { tailed })\end{array}$} \\
\hline & & Mean & $\begin{array}{l}\text { Std. } \\
\text { Deviation }\end{array}$ & $\begin{array}{c}\text { Std. } \\
\text { Error } \\
\text { Mean }\end{array}$ & $\begin{array}{l}95 \% \\
\text { Confide } \\
\text { Interval } \\
\text { Differer }\end{array}$ & $\begin{array}{l}\text { ence } \\
1 \text { of the } \\
\text { nce }\end{array}$ & & & \\
\hline & & & & & Lower & Upper & & & \\
\hline Pair 1 & $\begin{array}{l}\text { Denyut Nadi } \\
\text { Sebelum } \\
\text { Terpapar } \\
\text { Kebisingan } \\
\text { Denyut Nadi } \\
\text { Setelah Terpapar } \\
\text { Kebisingan } \\
\end{array}$ & -.800 & .422 & .133 & -1.102 & -.498 & -6.000 & 9 & .000 \\
\hline
\end{tabular}

